\title{
Influence of surface treatments and repair materials on the shear bond strength of CAD/CAM provisional restorations
}

\author{
Ki-Won Jeong, Sung-Hun Kim* \\ Department of Prosthodontics and Dental Research Institute, School of Dentistry, Seoul National University, Seoul, Republic of Korea
}

\begin{abstract}
PURPOSE. To evaluate the effect of surface treatments and repair materials on the shear bond strength and to measure the fracture toughness of CAD/CAM provisional restoration materials. MATERIALS AND METHODS. Four CAD/CAM (3D printing: Nextdent C\&B and ZMD-1000B Temporary, CAD/CAM resin block: Yamahachi PMMA disk and Huge PMMA block) and four conventional (monometacrylate: Jet and Alike, dimetacrylate: Luxatemp and Protemp 4) materials were selected to fabricate disk-shaped specimens and divided into six groups according to surface treatment $(n=10)$. CAD/CAM materials were repaired with Jet or Luxatemp, while conventional materials were repaired with their own materials. The shear bond strength was measured by using universal testing machine. Ten rectangular column-shaped specimens for each material were fabricated to measure the fracture toughness by single edge $v$ notched beam technique. Statistical analysis was performed by one-way ANOVA. RESULTS. The highest shear bond strength of CAD/CAM materials was achieved by SiC paper + sandblasting. It was also accomplished when repairing 3D printing materials with Luxatemp, and repairing CAD/CAM resin blocks with Jet. Yamahachi PMMA disk showed the highest fracture toughness. Nextdent C\&B showed the lowest fracture toughness value but no statistically significant difference from Alike and Luxatemp $(P>$.05). CONCLUSION. In order to successfully repair the CAD/CAM provisional restoration, mechanical surface treatment and appropriate repair material according to the CAD/CAM material type should be selected. The CAD/CAM provisional materials have proper mechanical properties for clinical use as compared to conventional materials. [J Adv Prosthodont 2019;11:95-104]
\end{abstract}

KEYWORDS: Computer-aided design; Computer-aided manufacturing; 3D printing; Provisional restoration; Shear bond strength

\section{INTRODUCTION}

Provisional restoration is an important process between tooth preparation and permanent setting procedure during fixed prosthetic treatment. ${ }^{1}$ Techniques for fabricating provisional restoration are divided into direct and indirect meth-

\section{Corresponding author:}

Sung-Hun Kim

Department of Prosthodontics and Dental Research Institute,

School of Dentistry, Seoul National University,

Daehakno 101, Jongno-gu, Seoul 03080, Republic of Korea

Tel. +82220722664: e-mail, ksh1250@snu.ac.kr

Received October 15, 2018 / Last Revision January 29, 2019 / Accepted March 12, 2019

(C) 2019 The Korean Academy of Prosthodontics

This is an Open Access article distributed under the terms of the Creative Commons Attribution Non-Commercial License (http://creativecommons. org/licenses/by-nc/4.0) which permits unrestricted non-commercial use, distribution, and reproduction in any medium, provided the original work is properly cited. ods. $^{2}$ The indirect method can avoid the damage of pulp and the surrounding tissue from heat and residual resin monomer. ${ }^{2}$ In addition, the polymerization shrinkage can be reduced because indirect method is progressed on a stone cast.

Recently, the use of computer-aided design/computeraided manufacturing (CAD/CAM) technology has been increasing to fabricate provisional restoration by indirect method. ${ }^{3}$ The CAD/CAM technology has reduced working time and amount of labor compared to the conventional method. ${ }^{4}$

There are subtractive and additive approaches to fabricate provisional restoration by CAD/CAM. ${ }^{5}$ The subtractive approach is three-dimensional milling of a resin block using a computer numeric controlled (CNC) machine. ${ }^{5}$ Since the resin blocks were polymerized with high degree of conversion, they have better physical properties and accuracy than direct methods. ${ }^{6-8}$ It is, however, impossible to pro- 
duce a very complicated restoration due to the technical limitations of the milling tools., ${ }^{9} 10$

The additive method, also called 3D printing or rapid prototyping, is a method of building a three-dimensional model by stacking layers of materials. ${ }^{3}$ The additive method makes it easy to fabricate complicated designs that could not be made by milling. It is also economical as only the necessary amounts of materials are used. ${ }^{10}$

The provisional restoration may be adjusted for correction of contour, proximal contact, and occlusion based on the treatment plan, improvement of aesthetics in the case of discoloration or defects, relining to improve the fit of the margin area, and repairing of damage. ${ }^{11,12}$ Although it would be ideal to remake the provisional restoration, it is economically advantageous to repair it at the chairside. ${ }^{13}$ If the provisional restoration fabricated by CAD/CAM method needs chairside modification, conventional monometacrylate or dimethacrylate based provisional materials are commonly used. A strong bond between the newly added material and the existing material is one of the most important factors for long-term use of the restoration. In addition, provisional restoration is exposed to various masticatory forces and occasionally to parafunctional habit, such as bruxism and clenching. Thus, it is important to fully understand the mechanical properties of provisional materials. Fracture toughness predicts the clinical performance of dental materials. High fracture toughness is essential for long-term stable use. ${ }^{14}$ There is, however, a lack of information on the fracture toughness of CAD/CAM provisional materials and compatibility with conventional materials.

The objectives of this study were (i) to evaluate the effect of surface treatment and repair material on the shear bond strength when CAD/CAM provisional materials (3D printing materials, CAD/CAM resin blocks) were repaired with conventional provisional materials, (ii) to measure the fracture toughness, and (iii) to compare their properties to conventional provisional materials. The null hypotheses to be tested are that 1) various surface treatments and types of repair materials do not affect to the shear bond strength in CAD/CAM provisional materials, and 2) shear bond strength and fracture toughness of CAD/CAM provisional materials are less than those of conventional materials.

\section{MATERIALS AND METHODS}

All of provisional restoration materials used in this study are presented in Table 1. Disk-shaped specimens of $7.5 \mathrm{~mm}$ in diameter and $2.0 \mathrm{~mm}$ in thickness for each CAD/CAM material were fabricated by using different manufacturing machines (Fig. 1A). ${ }^{15,16}$ Nextdent C\&B was fabricated using a 3D printer (W11, Bio3D, Seoul, Korea) by digital light processing (DLP) method. ZMD-1000B Temporary was fabricated using another 3D printer (Zenith U, Dentis, Daegu, Korea) by stereolithography (SLA) method. Yamahachi polymethyl methacrylate (PMMA) disk and Huge PMMA block was milled using a milling machine (Arum 5X-200, Doowon, Daejeon, Korea). Each specimen was embedded in a polytetrafluoroethylene (PTFE) mould with an outer diameter of $20 \mathrm{~mm}$, an inner diameter of $8.5 \mathrm{~mm}$, and a height of $11 \mathrm{~mm}$ using acrylic resin (Ortho-jet, Lot No. 144217BG, Lang, Wheeling, IL, USA). ${ }^{15,16}$ Luxatemp and Protemp 4 were injected into the mould with automixing gun applicators, while Jet and Alike were mixed with a clean plastic spatula for 20 seconds according to the manufacturer's instructions, and then immediately placed into the mould located on a flat glass plate. A vinyl strip was placed onto the mould and gentle hand pressure was applied to remove excess material. The specimens were allowed to polymerize at $23 \pm 1^{\circ} \mathrm{C}$ for 60 minutes. One hundred twenty specimens for each CAD/CAM material and sixty for each conventional material were fabricated. The CAD/CAM specimens were then divided into two groups of 60 specimens accord-

Table 1. Base and repair materials in this study

\begin{tabular}{|c|c|c|c|c|}
\hline Polymerization method & Material & Type & Lot number & Manufacturer \\
\hline \multirow{2}{*}{ 3D printing } & Nextdent C\&B & Monometacrylate (PMMA) & XR513N01 & $\begin{array}{l}\text { Vertex-Dental/Dentimex, } \\
\text { Zeist, Netherlands }\end{array}$ \\
\hline & ZMD-1000B Temporary & Monometacrylate (PMMA) & ZTP1204008 & Dentis, Daegu, Korea \\
\hline \multirow{2}{*}{$\begin{array}{l}\text { CAD/CAM resin block } \\
\text { milling }\end{array}$} & Yamahachi PMMA disk & Monometacrylate (PMMA) & Ml12 & YAMAHACHI, Aichi, Japan \\
\hline & Huge PMMA block & Monometacrylate (PMMA) & $\begin{array}{l}170320 Z \\
170403 Z\end{array}$ & Huge, Shandong, China \\
\hline \multirow{2}{*}{ Powder/liquid mix } & Jet & Monometacrylate (PMMA) & $\begin{array}{l}\text { 140417BC (Liquid) } \\
\text { 143016DP (Powder) }\end{array}$ & Lang, Wheeling, IL, USA \\
\hline & Alike & Monometacrylate (PMMA) & $\begin{array}{c}1703161 \text { (Liquid) } \\
1704241 \text { (Powder) }\end{array}$ & COE, Alsip, IL, USA \\
\hline \multirow{2}{*}{$\begin{array}{l}\text { Injection with } \\
\text { automixing gun }\end{array}$} & Luxatemp & Dimethacrylate (Bis-acrylic) & $\begin{array}{l}771712 \\
770230\end{array}$ & DMG, Hamburg, Germany \\
\hline & Protemp 4 & Dimethacrylate (Bis-acrylic) & $\begin{array}{l}3241302 \\
3248932\end{array}$ & 3M ESPE, St. Paul, MN, USA \\
\hline
\end{tabular}


ing to the repair material.

The specimens were randomly divided into six groups of 10 specimens and subjected to various surface treatments for clinical situation. Group with no treatment was set as a control group. Groups subjected to grinding with a 220-grit silicon carbide ( $\mathrm{SiC}$ ) paper (Waterproof Abrasive Paper, Daesung Abrasive Co., Seoul, Korea) and further surface treatments were set as experimental groups. After grinding, the specimens were subjected to ultrasonic cleaning in distilled water for 5 minutes. The surface treatments applied to the specimen were as follow:

(1) Control (CON): no treatment

(2) $\mathrm{SiC}$ paper $(\mathrm{SiC})$ : the 220 -grit $\mathrm{SiC}$ paper was reciprocated 50 times in one direction to grind about $2 \mu \mathrm{m}$.

(3) $\mathrm{SiC}$ paper+ sandblasting (S/SA): after grinding with $\mathrm{SiC}$ paper, $50 \mu \mathrm{m}$ aluminum oxide $\left(\mathrm{Al}_{2} \mathrm{O}_{3}\right)$ particles were sandblasted for 10 seconds at a distance of $10 \mathrm{~mm}$ from the airborne-particle abrasion device (S-U-PROGRESA 200, Schuler-Dental, Ulm, Germany)

(4) SiC papert hydrofluoric acid (S/HF): after grinding with $\mathrm{SiC}$ paper, a thin layer of $4 \%$ hydrofluoric acid gel (Porcelain etchant, Lot No. 1700003956, Bisco, Schaumburg, IL, USA) was applied for 120 seconds. It was rinsed with water for 120 seconds and then dried with oil-free compressed air for 10 seconds.

(5) $\mathrm{SiC}$ paper+ adhesive (S/AD): after grinding with $\mathrm{SiC}$ paper, the bonding agent (Adper Scotchbond MultiPurpose adhesive, Lot No. N876942, 3M ESPE, St. Paul, MN, USA) was thinly applied with a brush and dried with oil-free compressed air for 5 seconds.

(6) $\mathrm{SiC}$ paper+ Single bond universal adhesive (S/SU): after grinding with $\mathrm{SiC}$ paper, the bonding agent (Single Bond universal adhesive, Lot No. 663411, 3M ESPE, St. Paul, MN, USA) was rubbed with a brush for 20 seconds and dried with oil-free compressed air for 5 seconds.

Additional specimens of each material were prepared for surface examination. The surface of each treated specimen was observed at $\times 500$ using a scanning electron microscope (FE-SEM, S-4700, Hitachi, Tokyo, Japan).

The repair procedure was performed using a stainless steel (SS) mould of $3 \mathrm{~mm}$ in diameter and $6 \mathrm{~mm}$ in height. The SS mould was placed on the treated surface and the fresh repair material was injected into the mould. The CAD/ CAM materials were repaired with the Jet and Luxatemp, while conventional materials were repaired with their own materials. A vinyl strip was placed onto the mould and gentle hand pressure was then applied to remove excess material. The repair resin was then polymerized at $23 \pm 1^{\circ} \mathrm{C}$ for 60 minutes. The specimens treated with the bonding agent were light cured for 10 seconds using an LED light curing machine (BeLite, B \& L Biotech, Ansan, Korea).

After polymerization, the specimen was removed gently from the SS mould (Fig. 1B), and then stored in distilled water at $37^{\circ} \mathrm{C}$ for 24 hours before measuring the shear bond strength. After 24 hours, specimens were immediately fixed on a shear test jig and firmly mounted on a universal testing machine (Instron, Model 3345, Canton, MA, USA). The knife-edge rod was then loaded at the crosshead speed of $0.5 \mathrm{~mm} / \mathrm{min}$ on the bonding interface (Fig. 1C). The maximum load was recorded when fracture occurred. The shear bond strength was then measured by applying the obtained values into the following formula:

$$
\sigma=\mathrm{F} / \mathrm{A}
$$

where $\sigma$ is the bond strength $(\mathrm{MPa}), \mathrm{F}$ is the load at failure $(\mathrm{N})$, and $\mathrm{A}$ is the repaired area $\left(\mathrm{mm}^{2}\right)$.

The fracture surface of each specimen was examined with a stereoscopic microscope (BH-2, Olympus, Tokyo, Japan) and divided into adhesive, cohesive, and mixed failure. Adhesive failure was determined when less than $10 \%$ of the repair resin remained. Cohesive failure was determined when more than $50 \%$ of the provisional base material was fractured. Mixed failure was the intermediate between the two failure mode. ${ }^{17}$

The fracture toughness was measured by single edge $\mathrm{v}$ notched beam (SEVNB) technique. A $36 \mathrm{~mm} \times 8 \mathrm{~mm} \times 4$
A

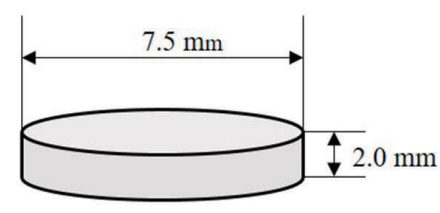

B

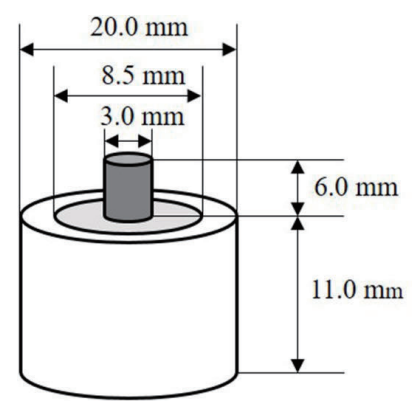

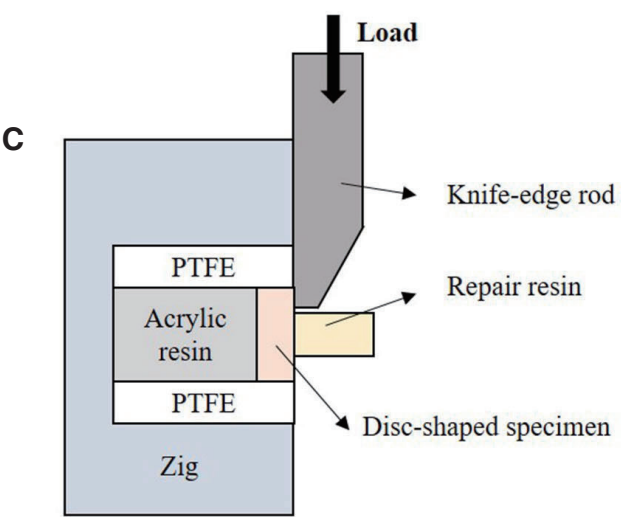

Fig. 1. Schematic diagrams of shear bond strength test. (A) Disk-shaped specimen, (B) PTFE mould embedded disk-shaped specimen and adhered repair resin, (C) Assembly of shear bond test zig. 


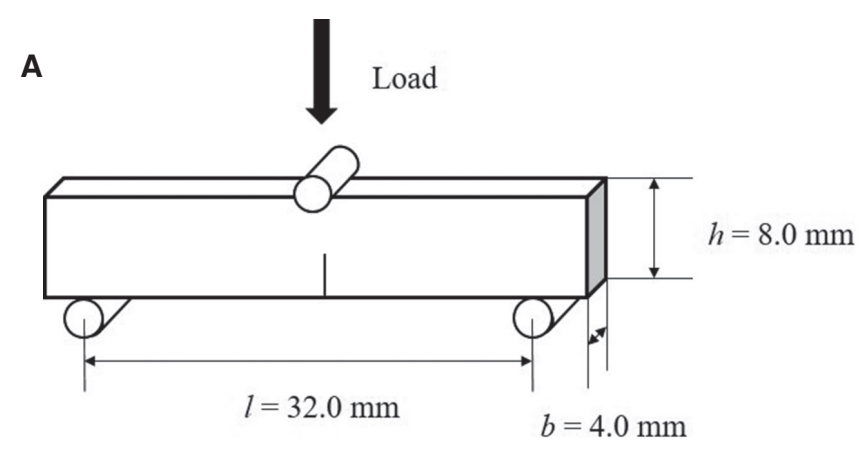

B

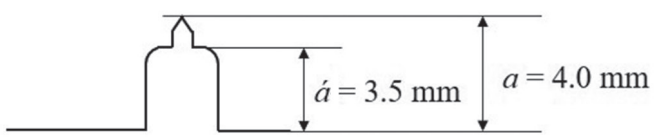

Fig. 2. Schematic diagrams of specimen used in fracture toughness test (single edge $v$ notched beam technique). (A) Rectangular column-shaped specimen, (B) Magnified precrack.

$\mathrm{mm}$ rectangular column-shaped specimens for each material were prepared (Fig. 2A). At the center of the specimen, a diamond wheel (Diamond disc, Edenta AG, AU/SG, Switzerland) was used to form a precrack of $3 \mathrm{~mm}$ in length at a circumferential speed of about 15,000 rpm. After dropping the glycerol into the precrack, a microcrack with a length of 0.1 to $0.4 \mathrm{~mm}$ was formed by a sliding motion using a scalpel blade (Surgical blade, Ribbel, New Delhi, India) (Fig. 2B). The length of the crack was measured in three parts of the specimen and the average value was obtained. The ratio of the height to the crack length $(\mathrm{a} / \mathrm{h})$ was in the range of 0.45 to $0.55 .{ }^{18}$ After ultrasonic cleansing, the specimens were stored at $37^{\circ} \mathrm{C}$ for 7 days. They were taken out and stored at $23^{\circ} \mathrm{C}$ for 1 hour before mechanical testing. After 1 hour, fracture toughness test was performed at a cross-head speed of $0.5 \mathrm{~mm} / \mathrm{min}$ in a universal testing machine. Maximum load to fracture was recorded and the fracture toughness was calculated by the following equation ${ }^{18}$ :

$$
\begin{gathered}
K_{I c}=\left(f P_{\text {max }} l / h b^{1.5}\right) \times \sqrt{10^{-3}} \\
f(\mathrm{x})=3 x^{0.5} \frac{\left[1.99-x(1-x)\left(2.15-3.93 x+2.7 x^{2}\right]\right.}{2(1+2 x)(1-x)^{1.5}}
\end{gathered}
$$

where $P_{\text {max }}$ is the maximum load $(\mathrm{kN}), l$ is the span length $(\mathrm{mm})$, and $h, b$ are specimen height and width (mm).

The mean values and standard deviations of the results were calculated. The data were analyzed using one-way ANOVA and multiple comparison Scheffés post hoc test. For all statistical analyses, a significance level of 0.05 was used (SPSS 25, SPSS Inc., Chicago, IL, USA).

\section{RESULTS}

Shear bond strength of each material and mean and standard deviation of all materials are presented in Table 2. It was noted that bonding did not occur when the bis-acrylic resin was used as a repair material after Single Bond universal treatment.
In Nextdent C\&B and ZMD-1000B Temporary, group $\mathrm{S} / \mathrm{SA}$ showed the highest mean shear bond strength values. The mean shear bond strength values of both materials were also higher when Luxatemp was used as repair material.

In Yamahachi PMMA disk and Huge PMMA block, on the other hand, the mean shear bond strength values were higher when Jet was used as repair material. Both materials showed the highest mean shear bond strength values in group S/SA like 3D printing materials.

Jet and Alike showed the highest mean shear bond strength values in the group S/SA, while Luxatemp and Protemp 4 showed the highest value in group $\mathrm{S} / \mathrm{HF}$.

The SEM images of CAD/CAM materials are presented in Fig. 3 to Fig. 6. Different topographic patterns were observed depending on the fabricating method and the surface treatment. The 3D printing material was layered and the $\mathrm{CAD} / \mathrm{CAM}$ resin block was milled during the fabricating procedure, so lines on the surface of the specimen were observed in a certain direction in the control groups. In the groups grinded with $\mathrm{SiC}$ paper, long grooves, which are macroretentive features, were observed. When hydrofluoric acid gel was applied, smooth edges, dissolved fillers, and irregular porous forms were observed especially noticeable in bis-acrylic resins. In sandblast treatment after $\mathrm{SiC}$ paper grinding, micromechanical retention systems, such as irregular surface and many channels, were observed.

The failure modes of all groups in this study were shown graphically in Fig. 7. When the 3D printing material was repaired by Luxatemp and the CAD/CAM resin block was repaired by Jet, cohesive failure was more frequent. It was also observed when mechanical surface treatment, especially sandblasting was treated.

The mean fracture toughness values of the materials were presented in Table 3. Yamahachi PMMA disk showed the highest mean fracture toughness value and Huge PMMA block was the second highest. The 3D printing materials showed the lowest values, but there was no statistical difference from Alike and Luxatemp $(P>.05)$. 
Table 2. Mean shear bond strength $(\mathrm{MPa})$ with standard deviations for each material in the treatment

\begin{tabular}{|c|c|c|c|c|c|c|c|c|c|c|c|c|}
\hline \multirow{2}{*}{ Treatment } & \multicolumn{2}{|c|}{$\mathrm{Ne}^{*}$} & \multicolumn{2}{|c|}{$\mathrm{ZM}^{*}$} & \multicolumn{2}{|c|}{$Y A^{*}$} & \multicolumn{2}{|c|}{$H U^{*}$} & \multirow[t]{2}{*}{$J e^{\star}$} & \multirow[t]{2}{*}{$\mathrm{Al}^{*}$} & \multirow[t]{2}{*}{$\mathrm{Lu}^{*}$} & \multirow[t]{2}{*}{ Pro* } \\
\hline & Je & Lu & Je & Lu & Je & Lu & Je & Lu & & & & \\
\hline $\mathrm{CON}$ & $\begin{array}{c}13.96 \\
(1.89)^{a}\end{array}$ & $\begin{array}{l}23.18 \\
(2.81)^{b}\end{array}$ & $\begin{array}{l}22.05 \\
(3.02)^{f}\end{array}$ & $\begin{array}{l}33.69 \\
(1.43)^{h}\end{array}$ & $\begin{array}{c}16.79 \\
(3.06)^{\mathrm{k}}\end{array}$ & $\begin{array}{c}4.18 \\
(1.57)^{\mathrm{m}}\end{array}$ & $\begin{array}{l}25.68 \\
(3.31)^{p}\end{array}$ & $\begin{array}{c}3.01 \\
(1.90)^{\mathrm{s}}\end{array}$ & $\begin{array}{l}34.01 \\
(4.16)^{w}\end{array}$ & $\begin{array}{l}32.33 \\
(2.40)^{x}\end{array}$ & $\begin{array}{l}37.63 \\
(5.10)^{z}\end{array}$ & $\begin{array}{c}40.86 \\
(6.01)^{\circledR}\end{array}$ \\
\hline $\mathrm{SiC}$ & $\begin{array}{c}16.62 \\
(3.12)^{a}\end{array}$ & $\begin{array}{l}28.28 \\
(3.48)^{c}\end{array}$ & $\begin{array}{l}22.22 \\
(3.12)^{f}\end{array}$ & $\begin{array}{l}40.45 \\
(5.40)^{i}\end{array}$ & $\begin{array}{l}29.58 \\
(2.81)^{\prime}\end{array}$ & $\begin{array}{c}10.42 \\
(3.38)^{n}\end{array}$ & $\begin{array}{c}29.95 \\
(3.70)^{p q}\end{array}$ & $\begin{array}{c}9.89 \\
(2.85)^{\mathrm{tu}}\end{array}$ & $\begin{array}{l}33.27 \\
(2.01)^{w}\end{array}$ & $\begin{array}{l}34.69 \\
(2.04)^{x}\end{array}$ & $\begin{array}{l}40.49 \\
(4.71)^{z}\end{array}$ & $\begin{array}{c}44.29 \\
(4.70)^{\Theta}\end{array}$ \\
\hline S/SA & $\begin{array}{c}17.72 \\
(2.58)^{\mathrm{a}}\end{array}$ & $\begin{array}{l}32.98 \\
(2.12)^{d}\end{array}$ & $\begin{array}{l}24.00 \\
(3.41)^{f}\end{array}$ & $\begin{array}{l}44.09 \\
(3.36)^{i}\end{array}$ & $\begin{array}{l}29.93 \\
(3.88)^{\prime}\end{array}$ & $\begin{array}{c}13.80 \\
(2.04)^{n}\end{array}$ & $\begin{array}{l}32.89 \\
(4.02)^{a}\end{array}$ & $\begin{array}{l}12.37 \\
(4.39)^{t}\end{array}$ & $\begin{array}{c}36.74 \\
(3.87)^{\mathrm{w}}\end{array}$ & $\begin{array}{l}39.67 \\
(2.78)^{y}\end{array}$ & $\begin{array}{l}41.54 \\
(5.97)^{z}\end{array}$ & $\begin{array}{c}46.07 \\
(2.63)^{\Theta}\end{array}$ \\
\hline $\mathrm{S} / \mathrm{HF}$ & $\begin{array}{c}14.61 \\
(3.73)^{\mathrm{a}}\end{array}$ & $\begin{array}{c}25.08 \\
(4.68)^{b c}\end{array}$ & $\begin{array}{c}18.78 \\
(2.21)^{\mathrm{fg}}\end{array}$ & $\begin{array}{l}38.86 \\
(4.82)^{\mathrm{hi}}\end{array}$ & $\begin{array}{l}29.70 \\
(1.99)^{\prime}\end{array}$ & $\begin{array}{c}12.69 \\
(2.24)^{n}\end{array}$ & $\begin{array}{l}27.47 \\
(2.05)^{p r}\end{array}$ & $\begin{array}{c}7.87 \\
(1.31)^{\mathrm{u}}\end{array}$ & $\begin{array}{l}33.64 \\
(3.07)^{w}\end{array}$ & $\begin{array}{l}34.69 \\
(3.97)^{x}\end{array}$ & $\begin{array}{l}43.00 \\
(8.19)^{2}\end{array}$ & $\begin{array}{c}49.08 \\
(4.60)^{\#}\end{array}$ \\
\hline$S / A D$ & $\begin{array}{c}17.22 \\
(2.95)^{\mathrm{a}}\end{array}$ & $\begin{array}{c}16.56 \\
(2.27)^{\mathrm{e}}\end{array}$ & $\begin{array}{l}22.11 \\
(4.78)^{f}\end{array}$ & $\begin{array}{c}17.24 \\
(1.56)^{j}\end{array}$ & $\begin{array}{l}29.39 \\
(1.93)^{\prime}\end{array}$ & $\begin{array}{l}19.21 \\
(2.97)^{\circ}\end{array}$ & $\begin{array}{c}30.91 \\
(1.92)^{v}\end{array}$ & $\begin{array}{l}17.07 \\
(2.91)^{v}\end{array}$ & $\begin{array}{l}33.91 \\
(4.15)^{\mathrm{w}}\end{array}$ & $\begin{array}{l}34.07 \\
(1.90)^{x}\end{array}$ & $\begin{array}{l}40.79 \\
(5.09)^{2}\end{array}$ & $\begin{array}{c}45.81 \\
(5.00)^{\Theta}\end{array}$ \\
\hline S/SU & $\begin{array}{c}13.83 \\
(2.89)^{a}\end{array}$ & & $\begin{array}{c}16.59 \\
(4.02)^{\mathrm{g}}\end{array}$ & & $\begin{array}{l}29.56 \\
(1.79)^{\prime}\end{array}$ & & $\begin{array}{c}29.78 \\
(3.31)^{p q}\end{array}$ & & $\begin{array}{l}33.20 \\
(2.27)^{w}\end{array}$ & $\begin{array}{l}33.99 \\
(2.27)^{\times}\end{array}$ & & \\
\hline
\end{tabular}

* Ne Nextdent C\&B; ZM ZMD-1000B Temporary; YA Yamahachi PMMA disk; HU Huge PMMA block; JE Jet; Al Alike; Lu Luxatemp; Pro Protemp 4

Superscripts show no significant differences at $P>.05$.
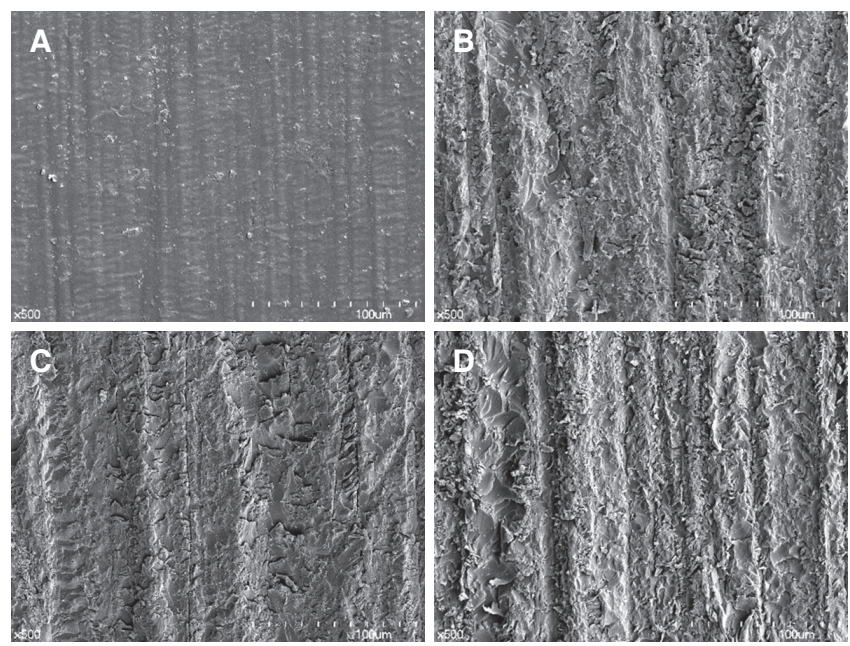

Fig. 3. Scanning electron micrographs (magnification $\times 500)$ of Nextdent C\&B specimen surfaces: (A) Control; (B) Grinding with 220-grit SiC paper; (C) Grinding with 220grit $\mathrm{SiC}$ paper + sandblasting with $50 \mu \mathrm{m} \mathrm{Al} \mathrm{O}_{3}$; (D) Grinding with 220-grit SiC paper + etching with 4\% hydrofluoric acid.

\section{DISCUSSION}

The provisional restoration may be adjusted for repair or relining procedure at the chairside and the repaired provisional restoration should be maintained until definitive treatment is placed. To improve the bond strength, the surface roughness should be increased to promote mechanical interlocking, or the bonding agent may be applied to increase the wettability and induce chemical bonding. ${ }^{19}$ Choice of the proper repair material is also critical point. Thus, in this study, mechanical methods including silicon carbide (SiC)
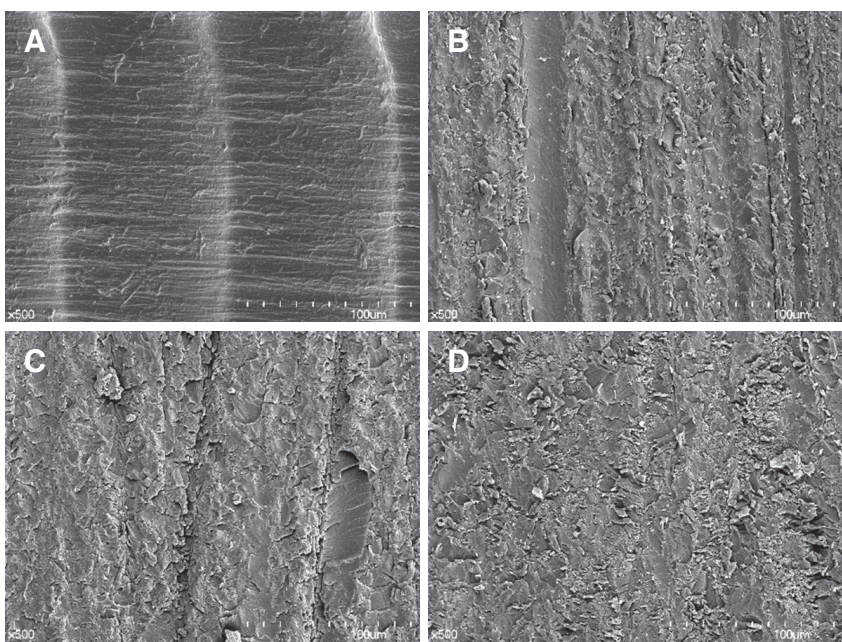

Fig. 4. Scanning electron micrographs (magnification $\times 500$ ) of ZMD-1000B Temporary specimen surfaces: (A) Control; (B) Grinding with 220-grit SiC paper; (C) Grinding with 220-grit SiC paper + sandblasting with 50 $\mu \mathrm{m} \mathrm{Al} \mathrm{O}_{3}$; (D) Grinding with 220-grit SiC paper + etching with $4 \%$ hydrofluoric acid.

paper grinding, $5 \mu \mathrm{m} \mathrm{Al}_{2} \mathrm{O}_{3}$ sandblasting, and 4\% hydrofluoric acid etching and chemical methods including the use of bonding agent and adhesive containing silane were chosen for increasing surface roughness. The reason for choosing these treatments was that they could be simply and frequently used in all dental clinics. ${ }^{16,19-23}$ Especially, grinding with carbide or diamond bur is the essential process for removing the contamination on surface and preparing a uniform space for the added material when the provisional restoration was repairing or relining. Thus, grinding was selected as the base treatment and included in all groups. For 

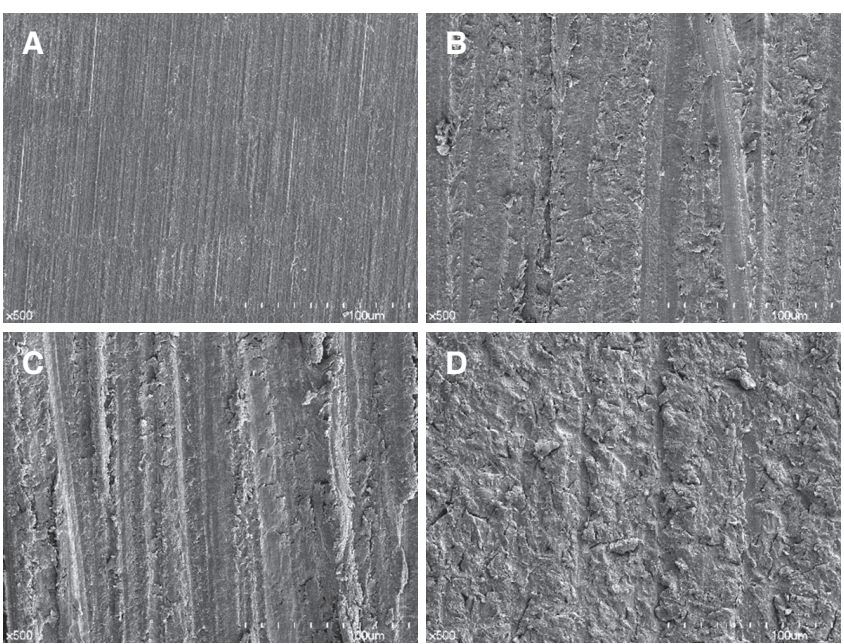

Fig. 5. Scanning electron micrographs (magnification $\times 500$ ) of Yamahachi PMMA disk specimen surfaces: (A) Control; (B) Grinding with 220-grit SiC paper; (C) Grinding with 220-grit SiC paper + sandblasting with $50 \mu \mathrm{m} \mathrm{Al}{ }_{2} \mathrm{O}_{3}$; (D) Grinding with 220-grit SiC paper + etching with $4 \%$ hydrofluoric acid.
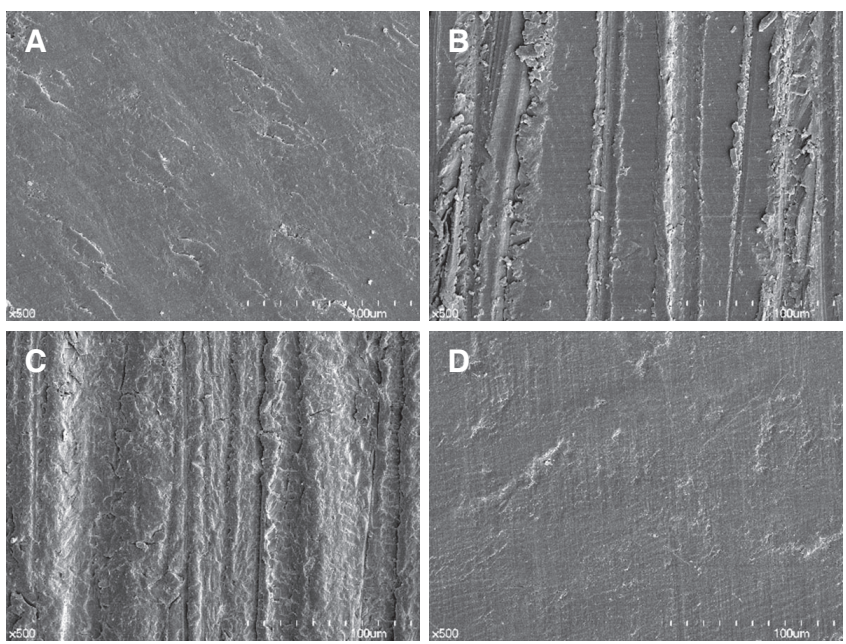

Fig. 6. Scanning electron micrographs (magnification $\times 500$ ) of Huge PMMA block specimen surfaces: (A) Control; (B) Grinding with 220-grit SiC paper; (C) Grinding with 220grit $\mathrm{SiC}$ paper + sandblasting with $50 \mu \mathrm{m} \mathrm{Al} \mathrm{O}_{3}$; (D) Grinding with 220-grit SiC paper + etching with 4\% hydrofluoric acid.
A

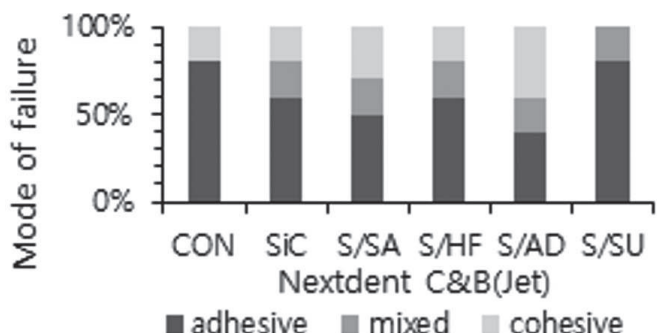

C

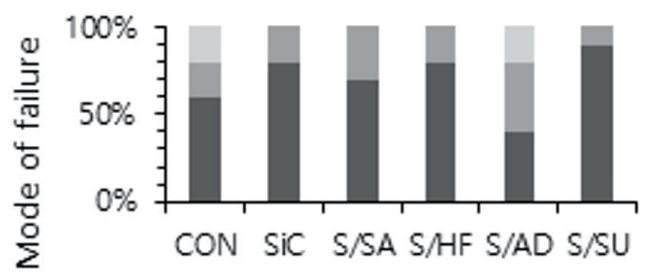

ZMD-1000B Temporary(Jet) adhesive mixed $n$ cohesive

E

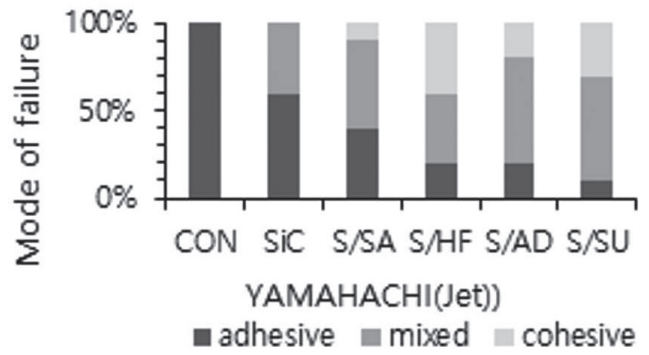

B

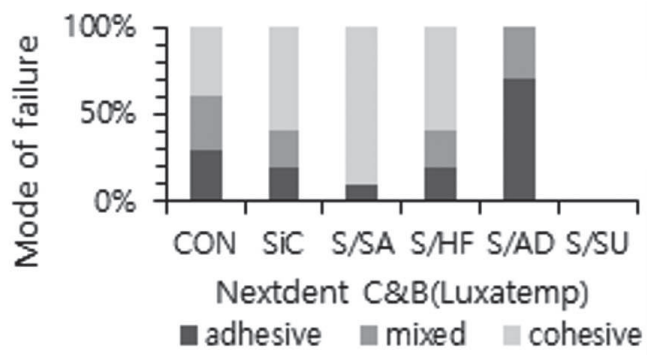

D

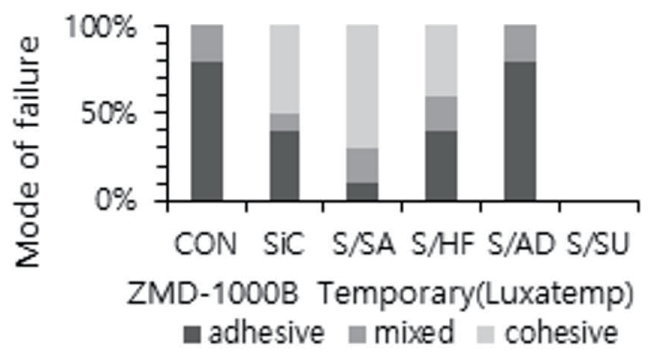

$\mathbf{F}$

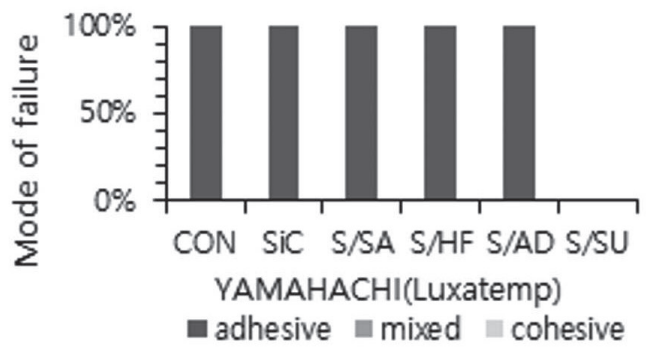

Fig. 7. Distribution (percentage) of failure mode for each material in the treatment: (A) Nextdent C\&B specimen repaired with Jet; (B) Nextdent C\&B specimen repaired with Luxatemp; (C) ZDM-1000B temporary specimen repaired with Jet; (D) ZDM-1000B temporary specimen repaired with Luxatemp; (E) Yamahachi PMMA disk specimen repaired with Jet; (F) Yamahachi PMMA disk specimen repaired with Luxatemp. 
G

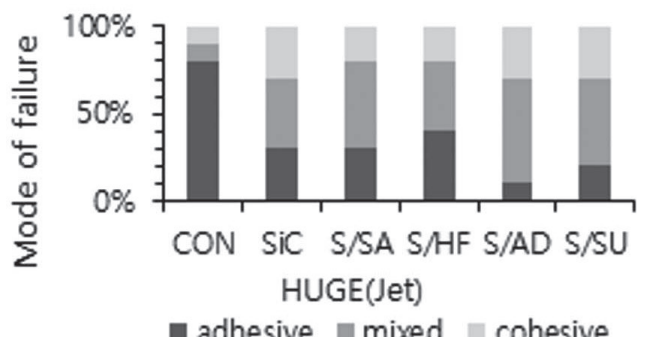

I

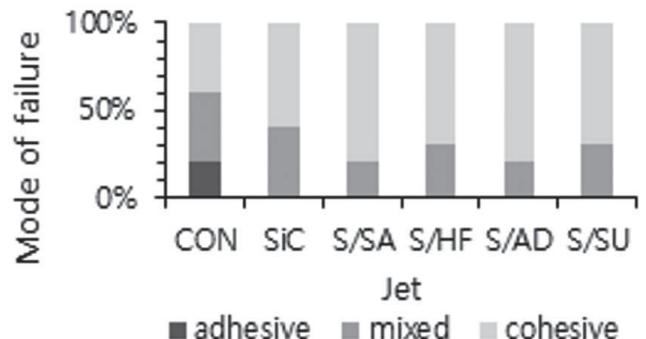

K

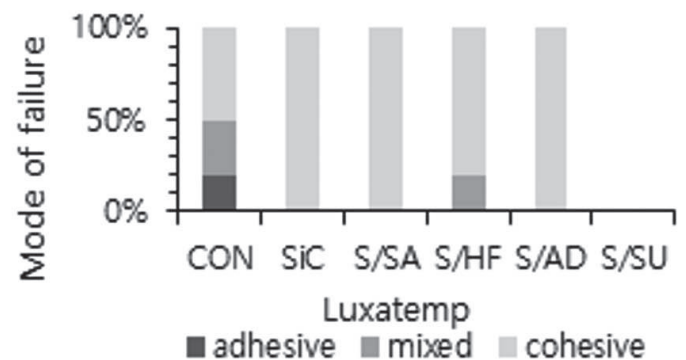

H

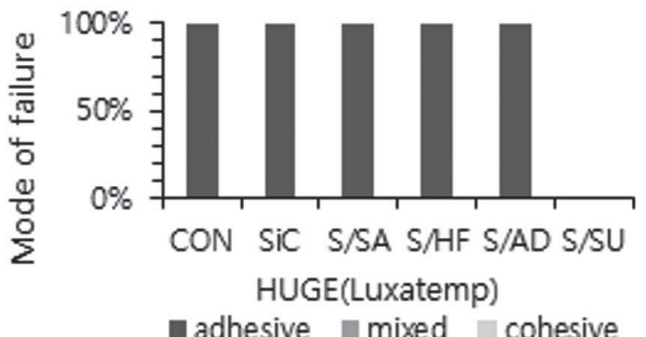

$\mathbf{J}$

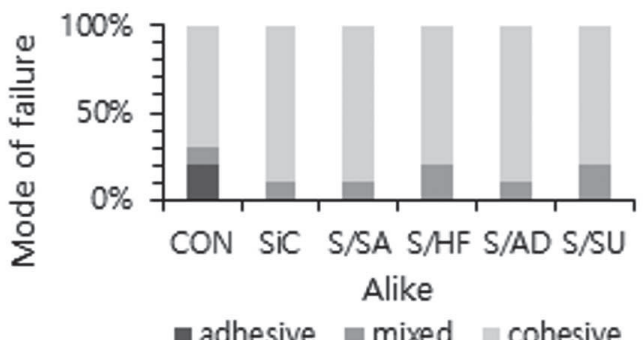

$\mathbf{L}$

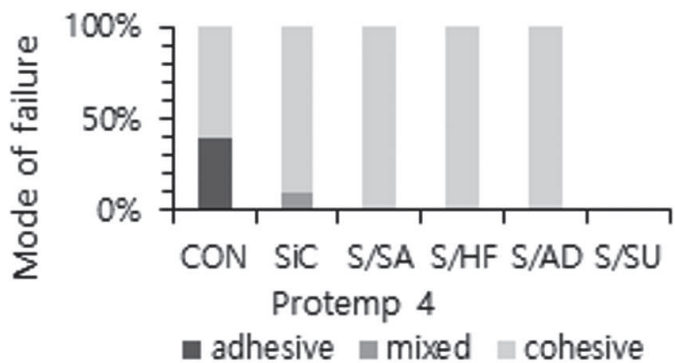

Fig. 7. (Continued) Distribution (percentage) of failure mode for each material in the treatment: (G) Huge PMMA block specimen repaired with Jet; $(\mathrm{H})$ Huge PMMA block specimen repaired with Luxatemp; (I) Jet specimen repaired with Jet; (J) Alike specimen repaired with Alike; (K) Luxatemp specimen repaired with Luxatempt; (L) Protemp 4 specimen repaired with Protemp 4.

Table 3. Fracture toughness $\left(\mathrm{MPa} \cdot \mathrm{m}^{1 / 2}\right)$ with standard deviations for each material

\begin{tabular}{ccccccccc}
\hline Group & $\mathrm{Ne}^{*}$ & $\mathrm{ZM}^{*}$ & $\mathrm{YA}^{*}$ & $\mathrm{HU}^{*}$ & $\mathrm{Je}^{*}$ & $\mathrm{Al}^{*}$ & $\mathrm{Lu}^{*}$ & $\mathrm{PrO}^{*}$ \\
\hline $\begin{array}{c}\text { Fracture toughness } \\
\left(\mathrm{MPa} \cdot \mathrm{m}^{1 / 2}\right)\end{array}$ & 1.5 & 1.52 & 3.08 & 2.67 & 1.91 & 1.62 & 1.60 & 2.00 \\
$(0.24)^{\mathrm{a}}$ & $(0.19)^{\mathrm{a}}$ & $(0.16)^{\mathrm{b}}$ & $(0.12)^{\mathrm{c}}$ & $(0.23)^{\mathrm{d}}$ & $(0.22)^{\mathrm{ad}}$ & $(0.09)^{\mathrm{ad}}$ & $(0.23)^{\mathrm{d}}$ \\
\hline
\end{tabular}

* Ne Nextdent C\&B; ZM ZMD-1000B Temporary; YA Yamahachi PMMA disk; HU Huge PMMA block; JE Jet; Al Alike; Lu Luxatemp; Pro Protemp 4

Superscripts show no significant differences at $P>.05$.

grinding procedure, $\mathrm{SiC}$ paper was selected to replace a carbide or fine diamond bur..$^{24}$ It has the advantage that it can give more uniform and stable force and is easy to apply than carbide or diamond bur in laboratory research. Lee $e t$ al. proposed the use of 220 -grit $\mathrm{SiC}$ paper for this purpose. ${ }^{25}$ Combination of three or more treatments was also excluded as it was economically disadvantageous in clinical situation. Conventional methacrylate-based provisional materials such as Jet and Luxatemp were selected as repair materials. The reason for choosing these materials is that they had been verified over the long-term and were one of the most widely used materials in clinical practice. They were also more economical than Alike and Protemp 4, respectively.

The shear bond strength of group $\mathrm{SiC}$ was higher than that of group CON in most of the materials because of macro retentive features such as long grooves on the surface. ${ }^{19}$ However, group CON of Jet showed opposite results. It is because a number of air bubbles that could be effective 
in increasing surface roughness have been generated, even though vibrator is used for mixing process. But in other groups of Jet, it was confirmed that the surface bubbles were mostly removed by $\mathrm{SiC}$ paper grinding. There was also the possibility that grinding debris reduced roughness. ${ }^{26}$

Sandblasting of the composite resin before repair procedure increases the bond strength by forming micro retentive features on the surface. ${ }^{19,27-29}$ Some studies have reported that the micromechanical retention was the most important factor in repairing the composite resin. ${ }^{27,30}$ In this study, it was confirmed that the group S/SA of all materials increased the shear bond strength as compared with the group SiC. Therefore, it is considered that sandblasting after $\mathrm{SiC}$ paper grinding is an effective surface treatment method to increase the bond strength.

Hydrofluoric acid gel (HF) etches glass particles in the matrix to form porous surfaces and gaps to provide micromechanical retention. ${ }^{31}$ In this study, it was found that the HF etching did not affect or rather reduced the bond strength in PMMA. It may result from the low amount of glass particles and the high hydrophobic monomer in PMMA. In addition, HF etching softened the PMMA surface that resulted in decreasing the surface roughness. ${ }^{20,32}$ On the contrary to PMMA materials, HF etching in bisacrylic resins such as Luxatemp and Protemp 4 increased the shear bond strength, as they contained more than $24 \%$ filler in the volume ratio of resin. It was verified from the results that all of bis-acrylic resins showed the highest mean shear bond strength values in group S/HF. The etching effect of HF depends on the amount and type of filler. If the components of the resin are not known accurately, routine use of HF should be avoided. . $^{2,31,32}$

Many studies have reported that the bond strength is increased when bonding agents is used. ${ }^{19,22,33-36}$ The polymers of the bonding agent flow into the microcrack of the polymer matrix to form a micro-entanglement. ${ }^{19,37}$ The bonding agent also improves the wettability of exposed filler particles and inhibits the formation of air voids. ${ }^{19,36,38}$ Some studies have shown that bond strength is increased when silane coupling agent is applied with bonding agent. ${ }^{19,39}$ Silane also improves the wettability of the adhesive system. ${ }^{31,40}$ In this study, the silane-free adhesive and Single bond universal, which was an all-in-one product with silane, were used as bonding agents. The results of this study showed that both of the bonding agents had almost no effect on bond strength. In the Single Bond universal treated group, the silane did not have any additional effect to bond strength and the bonding did not even occur when the bis-acrylic resin was used as the repair material. The reasons for this phenomenon are that: 1) the $\mathrm{pH}$ of the Single Bond universal is low by about 2.7 due to the presence of functional monomer. ${ }^{41}$ 2) there are few or no inorganic fillers in PMMA that react with silane. $^{31}$ 3) the Single Bond universal contains HEMA, a hydrophilic monomer that absorbs water, which cause swelling and weak bonding. ${ }^{42,43}$ Another interesting phenomenon is that the similar bond strength was obtained when the CAD/CAM materials were repaired with the bis-acrylic resin after the adhesive treatment. It is assumed that the adhesive flowed into the surface of the specimen was responsible for most of the bond strength than repair material.

The 3D printing materials showed a high bond strength when it was repaired with Luxatemp. Because Luxatemp flowing into the matrix formed a more complex network and a harder bond than Jet. On the other hand, the CAD/ CAM resin blocks showed the opposite results. As the resin blocks had a high degree of convergence and were composed of cross-linked PMMA, the bis-acrylic resin with a high molecular weight monomer was difficult to penetrate into the matrix.

The bond strength after repair procedure is determined by the number of unconverted $\mathrm{C}=\mathrm{C}$ double bonds that can react with the repair material. ${ }^{31}$ As time passes after the polymerization, the number of $\mathrm{C}=\mathrm{C}$ double bonds is decreased and cross-linking of the polymers is increased. It is then difficult for fresh monomer to penetrate into the matrix. ${ }^{16}$ The specimens of CAD/CAM materials used in this study had been prefabricated, while the specimens of conventional provisional materials were examined just after one hour of polymerization. Although conventional provisional materials have a lot of the unconverted $\mathrm{C}=\mathrm{C}$ double bonds, there was no statistically significant difference from CAD/CAM materials in the shear bond strength. As a result, the value of shear bond strength is clinically acceptable, when CAD/CAM materials were repaired at the chairside.

In clinical practice, the fracture of provisional restoration is caused by crack propagation that started from the surface. The fracture toughness is an appropriate parameter to measure the ability to resist various masticatory forces. ${ }^{44}$ Fahmy and Sharawi ${ }^{44}$ showed the highest fracture toughness of PMMA, followed by bis-GMA resin and PEMA. Balkenhol et al..$^{45}$ reported that the bond strength of the cross linked Protemp 3 Garant was higher than the notcross linked Trim. Tahayeri et al. ${ }^{46}$ reported that Nextdent $\mathrm{C} \& \mathrm{~B}$ has low physical properties due to a little amount of fillers but it is within the range that can be used in clinical practice. CAD/CAM resin blocks showed the highest fracture toughness. Although 3D printing materials showed the lowest values, it showed no statistically difference with Alike and Luxatemp $(P>.05)$. Thus, it is considered that the CAD/CAM materials have suitable fracture toughness for clinical use as compared to conventional materials.

\section{CONCLUSION}

Within the limitation of this study, the following conclusions were drawn. In order to successfully repair the CAD/ CAM provisional restoration, mechanical surface treatment and appropriate repair material according to the CAD/ CAM material type should be selected. The CAD/CAM provisional materials have proper mechanical properties for clinical use as compared to conventional materials. 


\section{ORCID}

Ki-Won Jeong https://orcid.org/0000-0002-5917-9434

Sung-Hun Kim https://orcid.org/0000-0003-3289-9703

\section{REFERENCES}

1. Orsi IA, Soares RG, Villabona CA, Panzeri H. Evaluation of the flexural strength and elastic modulus of resins used for temporary restorations reinforced with particulate glass fibre. Gerodontology 2012;29:e63-8.

2. Regish KM, Sharma D, Prithviraj DR. Techniques of fabrication of provisional restoration: an overview. Int J Dent 2011; 2011:134659.

3. Alharbi N, Osman R, Wismeijer D. Effects of build direction on the mechanical properties of 3D-printed complete coverage interim dental restorations. J Prosthet Dent 2016;115:7607.

4. Davidowitz G, Kotick PG. The use of CAD/CAM in dentistry. Dent Clin North Am 2011;55:559-70.

5. Lee WS, Lee DH, Lee KB. Evaluation of internal fit of interim crown fabricated with CAD/CAM milling and 3D printing system. J Adv Prosthodont 2017;9:265-70.

6. Stansbury JW, Idacavage MJ. 3D printing with polymers: Challenges among expanding options and opportunities. Dent Mater 2016;32:54-64.

7. Shamseddine L, Mortada R, Rifai K, Chidiac JJ. Marginal and internal fit of pressed ceramic crowns made from conventional and computer-aided design and computer-aided manufacturing wax patterns: An in vitro comparison. J Prosthet Dent 2016;116:242-8.

8. Park JM, Hong YS, Park EJ, Heo SJ, Oh N. Clinical evaluations of cast gold alloy, machinable zirconia, and semiprecious alloy crowns: A multicenter study. J Prosthet Dent 2016; 115:684-91.

9. Koch GK, Gallucci GO, Lee SJ. Accuracy in the digital workflow: From data acquisition to the digitally milled cast. J Prosthet Dent 2016;115:749-54.

10. Berman B. 3-D printing: The new industrial revolution. Business Horizons 2012;55:155-62.

11. Burns DR, Beck DA, Nelson SK; Committee on Research in Fixed Prosthodontics of the Academy of Fixed Prosthodontics. A review of selected dental literature on contemporary provisional fixed prosthodontic treatment: report of the Committee on Research in Fixed Prosthodontics of the Academy of Fixed Prosthodontics. J Prosthet Dent 2003;90:474-97.

12. Mai HN, Lee KB, Lee DH. Fit of interim crowns fabricated using photopolymer-jetting $3 \mathrm{D}$ printing. J Prosthet Dent 2017;118:208-15.

13. Koumjian JH, Nimmo A. Evaluation of fracture resistance of resins used for provisional restorations. J Prosthet Dent 1990;64:654-7.

14. Gegauff AG, Wilkerson JJ. Fracture toughness testing of visible light- and chemical-initiated provisional restoration resins. Int J Prosthodont 1995;8:62-8.

15. Moon JE, Kim SH, Lee JB, Han JS, Yeo IS, Ha SR. Effects of airborne-particle abrasion protocol choice on the surface characteristics of monolithic zirconia materials and the shear bond strength of resin cement. Ceram Int 2016;42:1552-62.

16. Ha SR, Kim SH, Lee JB, Han JS, Yeo IS. Improving shear bond strength of temporary crown and fixed dental prosthesis resins by surface treatments. J Mater Sci 2016;51:1463-75.

17. Chen HL, Lai YL, Chou IC, Hu CJ, Lee SY. Shear bond strength of provisional restoration materials repaired with light-cured resins. Oper Dent 2008;33:508-15.

18. Im YW, Jun SK, Kim SC, Kim DA, Kim GR, Kim NS, Lee HH. Standardized test methods for mechanical properties of dental prosthetic/restorative materials and their applications. Korean J Dent Mater 2015;42:259-70.

19. Brosh T, Pilo R, Bichacho N, Blutstein R. Effect of combinations of surface treatments and bonding agents on the bond strength of repaired composites. J Prosthet Dent 1997;77: 122-6.

20. Ozcan M. Evaluation of alternative intra-oral repair techniques for fractured ceramic-fused-to-metal restorations. J Oral Rehabil 2003;30:194-203.

21. Shahverdi S, Canay S, Sahin E, Bilge A. Effects of different surface treatment methods on the bond strength of composite resin to porcelain. J Oral Rehabil 1998;25:699-705.

22. Suliman AH, Swift EJ Jr, Perdigao J. Effects of surface treatment and bonding agents on bond strength of composite resin to porcelain. J Prosthet Dent 1993;70:118-20.

23. Cavalcanti AN, De Lima AF, Peris AR, Mitsui FH, Marchi GM. Effect of surface treatments and bonding agents on the bond strength of repaired composites. J Esthet Restor Dent 2007;19:90-8.

24. Ataol AS, Ergun G. Repair bond strength of resin composite to bilayer dental ceramics. J Adv Prosthodont. 2018;10:10112.

25. Lee YG, Moon SR, Cho YG. Effect of cutting instruments on the dentin bond strength of a self-etch adhesive. J Korean Acad Cons Dent 2010;35:13-9.

26. Gregory WA, Pounder B, Bakus E. Bond strengths of chemically dissimilar repaired composite resins. J Prosthet Dent 1990;64:664-8.

27. da Costa TR, Serrano AM, Atman AP, Loguercio AD, Reis A. Durability of composite repair using different surface treatments. J Dent 2012;40:513-21.

28. Özcan M, Corazza PH, Marocho SM, Barbosa SH, Bottino MA. Repair bond strength of microhybrid, nanohybrid and nanofilled resin composites: effect of substrate resin type, surface conditioning and ageing. Clin Oral Investig 2013;17: 1751-8.

29. Bacchi A, Consani RL, Sinhoreti MA, Feitosa VP, Cavalcante LM, Pfeifer CS, Schneider LF. Repair bond strength in aged methacrylate- and silorane-based composites. J Adhes Dent 2013;15:447-52.

30. Kimyai S, Oskoee SS, Mohammadi N, Rikhtegaran S, Bahari M, Oskoee PA, Vahedpour H. Effect of different mechanical and chemical surface treatments on the repaired bond strength of an indirect composite resin. Lasers Med Sci 2015; 30:6539.

31. Ozcan M, Alander P, Vallittu PK, Huysmans MC, Kalk W. Effect of three surface conditioning methods to improve 
bond strength of particulate filler resin composites. J Mater Sci Mater Med 2005;16:21-7.

32. Swift EJ Jr, LeValley BD, Boyer DB. Evaluation of new methods for composite repair. Dent Mater 1992;8:362-5.

33. Lucena-Martín C, González-López S, Navajas-Rodríguez de Mondelo JM. The effect of various surface treatments and bonding agents on the repaired strength of heat-treated composites. J Prosthet Dent 2001;86:481-8.

34. Oztas N, Alaçam A, Bardakçy Y. The effect of air abrasion with two new bonding agents on composite repair. Oper Dent 2003;28:149-54.

35. Azarbal P, Boyer DB, Chan KC. The effect of bonding agents on the interfacial bond strength of repaired composites. Dent Mater 1986;2:153-5.

36. Saunders WP1. Effect of fatigue upon the interfacial bond strength of repaired composite resins. J Dent 1990;18:158-62.

37. Crumpler DC, Bayne SC, Sockwell S, Brunson D, Roberson TM. Bonding to resurfaced posterior composites. Dent Mater 1989;5:417-24.

38. Eli I, Liberman R, Levi N, Haspel Y. Bond strength of joined posterior light-cured composites: comparison of surface treatments. J Prosthet Dent 1988;60:185-9.

39. Hisamatsu N, Atsuta M, Matsumura H. Effect of silane primers and unfilled resin bonding agents on repair bond strength of a prosthodontic microfilled composite. J Oral Rehabil 2002;29:644-8.

40. Ozcan M, Barbosa SH, Melo RM, Galhano GA, Bottino MA. Effect of surface conditioning methods on the microtensile bond strength of resin composite to composite after aging conditions. Dent Mater 2007;23:1276-82.

41. Lee HY, Han GJ, Chang J, Son HH. Bonding of the silane containing multi-mode universal adhesive for lithium disilicate ceramics. Restor Dent Endod 2017;42:95-104.

42. El Zohairy AA, De Gee AJ, Hassan FM, Feilzer AJ. The effect of adhesives with various degrees of hydrophilicity on resin ceramic bond durability. Dent Mater. 2004;20:778-87.

43. Takahashi M1, Nakajima M, Hosaka K, Ikeda M, Foxton RM, Tagami J. Long-term evaluation of water sorption and ultimate tensile strength of HEMA-containing/-free one-step self-etch adhesives. J Dent 2011;39:506-12.

44. Fahmy NZ, Sharawi A. Effect of two methods of reinforcement on the fracture strength of interim fixed partial dentures. J Prosthodont 2009;18:512-20.

45. Balkenhol M, Köhler H, Orbach K, Wöstmann B. Fracture toughness of cross-linked and non-cross-linked temporary crown and fixed partial denture materials. Dent Mater 2009; 25:917-28.

46. Tahayeri A, Morgan M, Fugolin AP, Bompolaki D, Athirasala A, Pfeifer CS, Ferracane JL, Bertassoni LE. 3D printed versus conventionally cured provisional crown and bridge dental materials. Dent Mater 2018;34:192-200. 